\title{
Erratum to: Mammalian pro-apoptotic bax gene enhances tobacco resistance to pathogens
}

Suomeng Dong $\cdot$ Zhengguang Zhang •

Xiaobo Zheng $\cdot$ Yuanchao Wang

Published online: 7 June 2011

(C) Springer-Verlag 2011

Erratum to: Plant Cell Rep (2008) 27:1559-1569

DOI 10.1007/s00299-008-0554-5

In the original version of the article, the first and last names of the authors were published in the wrong order. The correct author names are Suomeng Dong, Zhengguang Zhang, Xiaobo Zheng and Yuanchao Wang.

The online version of the original article can be found under doi:10.1007/s00299-008-0554-5.

S. Dong $\cdot$ Z. Zhang $\cdot$ X. Zheng $\cdot$ Y. Wang $(\bowtie)$

Department of Plant Pathology, Nanjing Agricultural University,

Nanjing 210095, China

e-mail: wangyc@njau.edu.cn 